\title{
Injection moulding antireflective nanostructures
}

Christiansen, Alexander Bruun; Clausen, Jeppe Sandvik; Mortensen, N. Asger; Kristensen, Anders

Publication date:

2013

Document Version

Publisher's PDF, also known as Version of record

Link back to DTU Orbit

Citation (APA):

Christiansen, A. B., Clausen, J. S., Mortensen, N. A., \& Kristensen, A. (2013). Injection moulding antireflective nanostructures. Poster session presented at 39th International Conference on Micro and Nano Engineering, London, United Kingdom.

\section{General rights}

Copyright and moral rights for the publications made accessible in the public portal are retained by the authors and/or other copyright owners and it is a condition of accessing publications that users recognise and abide by the legal requirements associated with these rights.

- Users may download and print one copy of any publication from the public portal for the purpose of private study or research.

- You may not further distribute the material or use it for any profit-making activity or commercial gain

- You may freely distribute the URL identifying the publication in the public portal

If you believe that this document breaches copyright please contact us providing details, and we will remove access to the work immediately and investigate your claim 


\section{Injection moulding antireflective nanostructures}

\section{Alexander Bruun Christiansen', Jeppe Clausen²,}

\section{N. Asger Mortensen" ${ }^{2}$, and Anders Kristensen ${ }^{1}$}

${ }^{1}$ DTU Nanotech Oersteds Plads Building 345 East DK 2800 Kongens Lyngby, ${ }^{2}$ DTU Fotonik, Technical University of Denmark

\section{Introduction}

Can expensive multilayer antireflective coatings for e.g. glasses and camera objectives be replaced by cheap nanostructured surfaces? Here we take one step in that direction, by injection moulding antireflective nanostructures on large areas, based on inexpensive, black silicon masters.

\section{Fabrication}

a) Black silicon is etched using reactive ion etching.

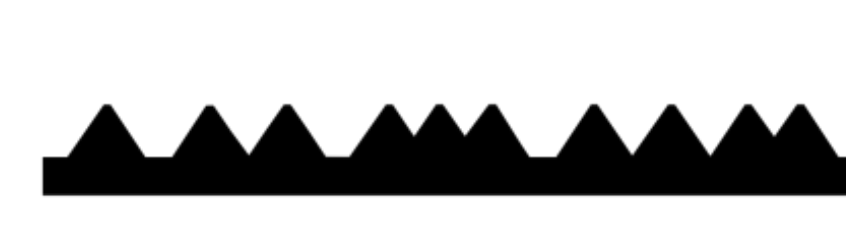

b) The black silicon is patterned using UV lithography.

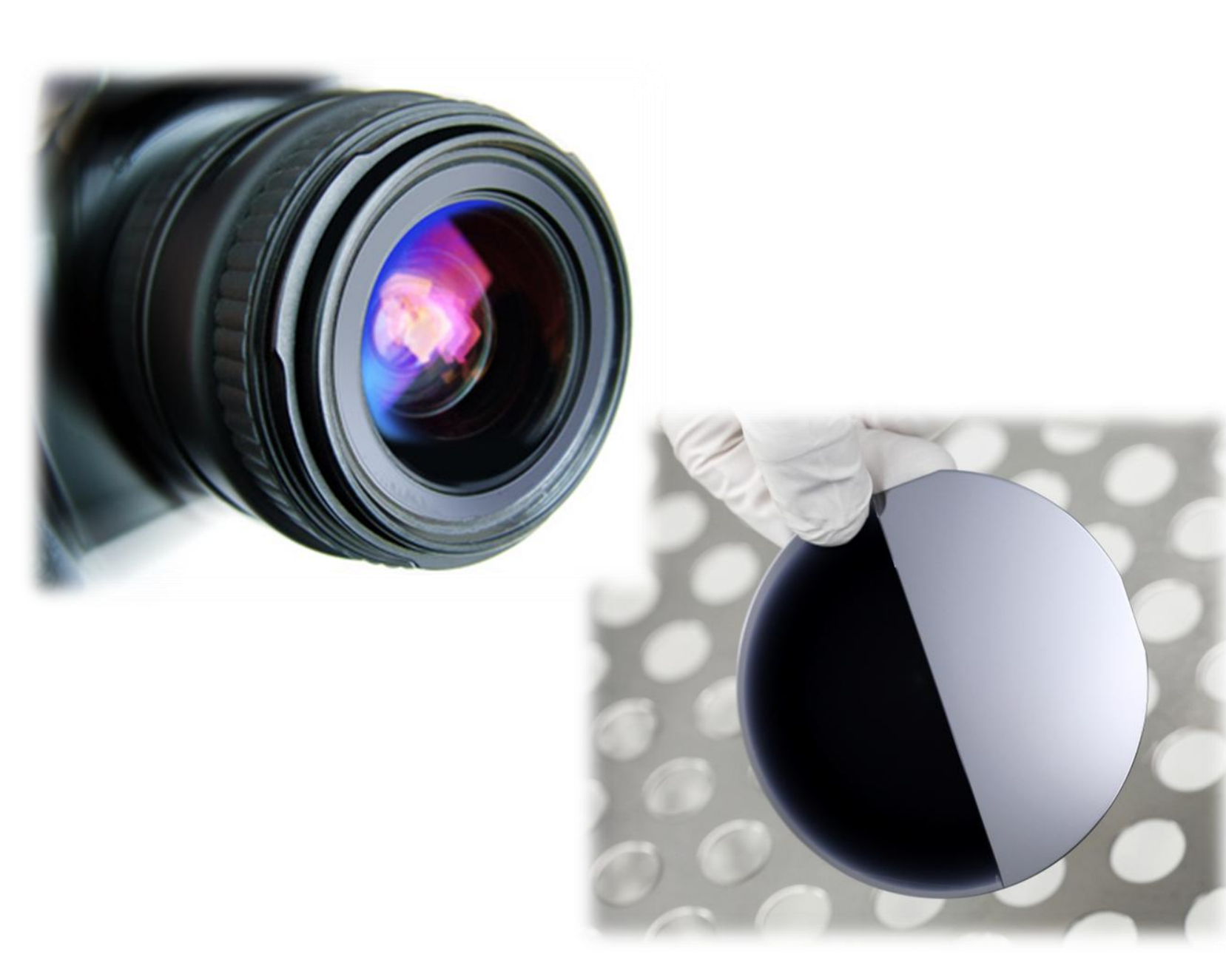

\section{c) A nickel shim is fabricated} from the black silicon master, using electroplating. The $\mathrm{Ni}$ shim is anti-stiction coated.

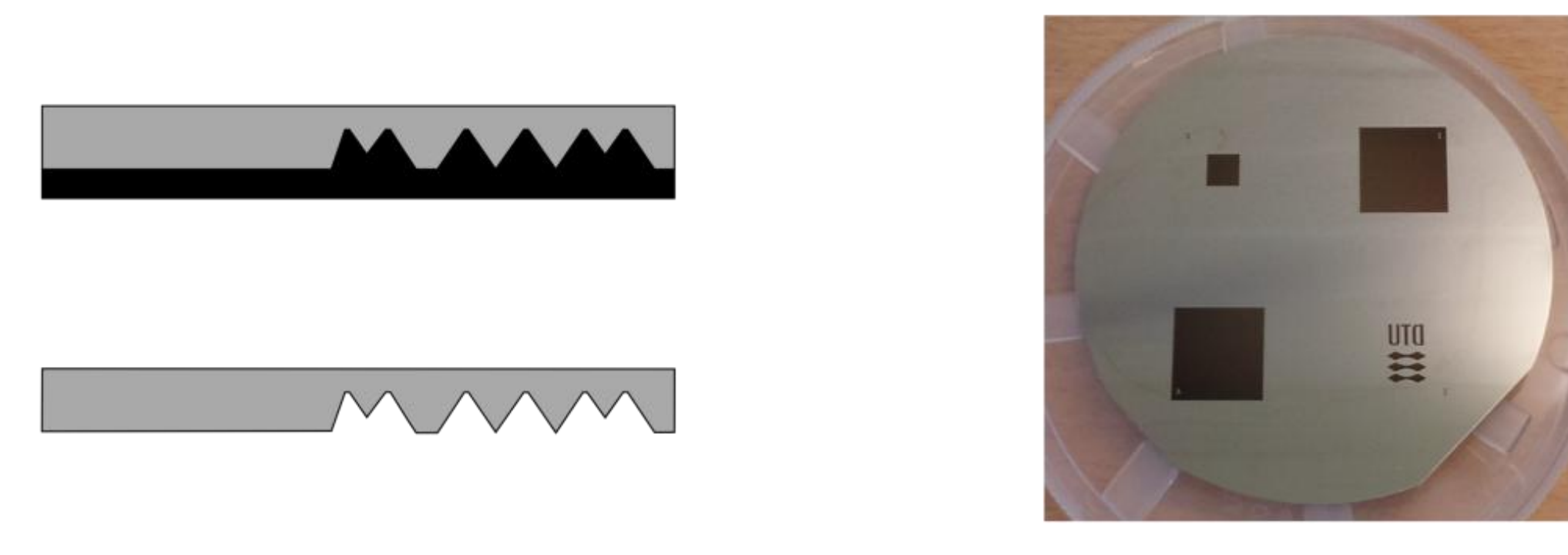

d) The nicklel shim is inserted in an injection moulding tool. The parts are being moulded with a cycle time of 30 seconds.
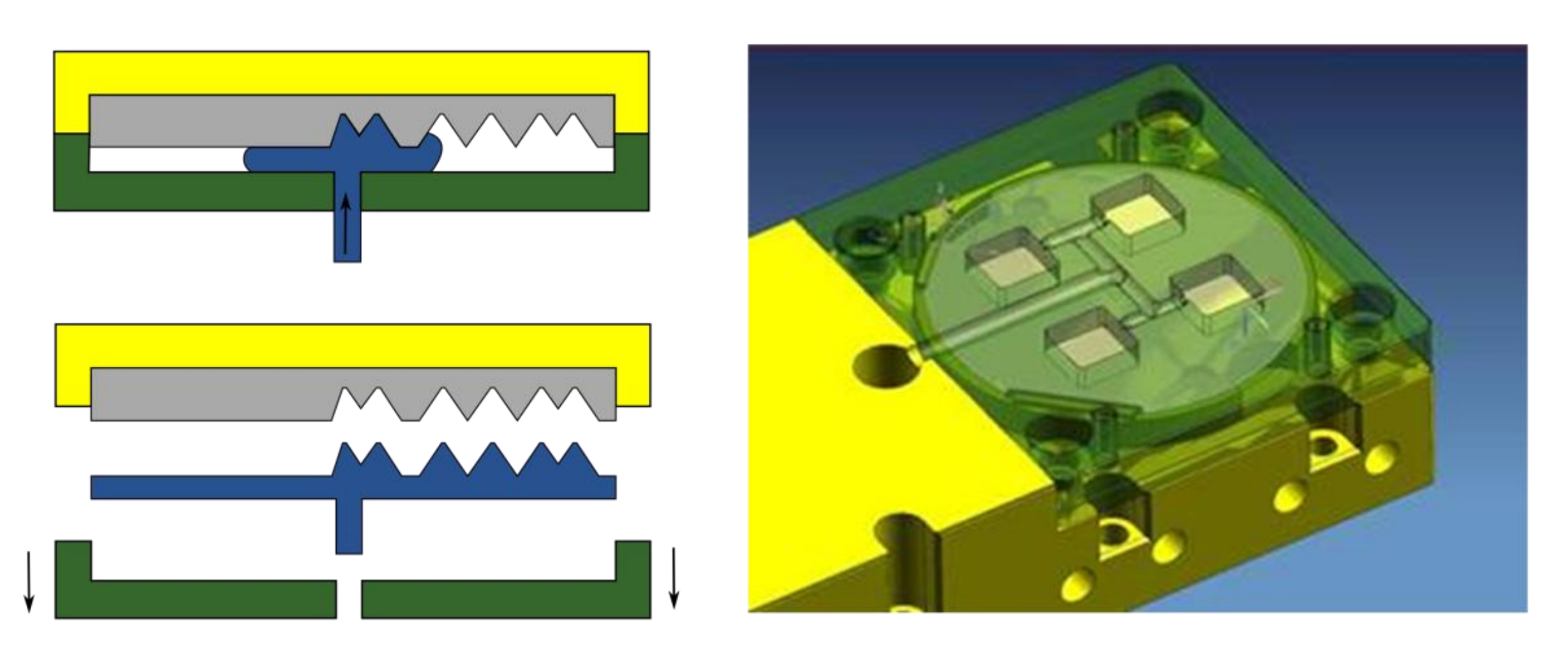

e) The final part in a black polymer. The antireflective nanostructures are seen as dark areas.
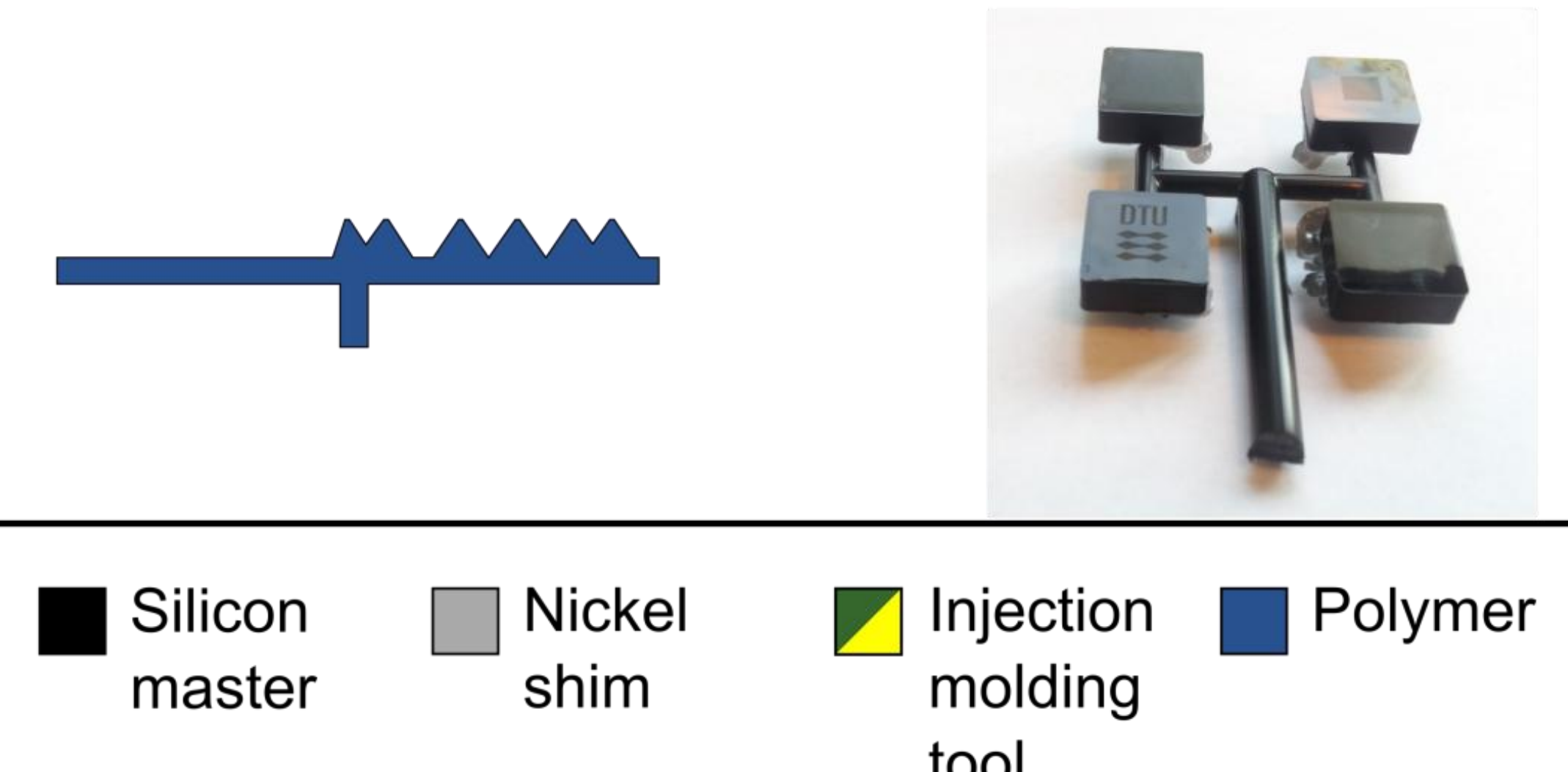

\section{Background}

In previous work [1], black silicon has been used for fabricating antireflective surfaces on transparent substrates. The nanostructures were optimized for maximum transmission of light. Control of the lateral size of the structures was crucial in order to avoid scattering from the random black silicon surface. A characteristic period below $160 \mathrm{~nm}$ was nescessary in order to avoid scattering.

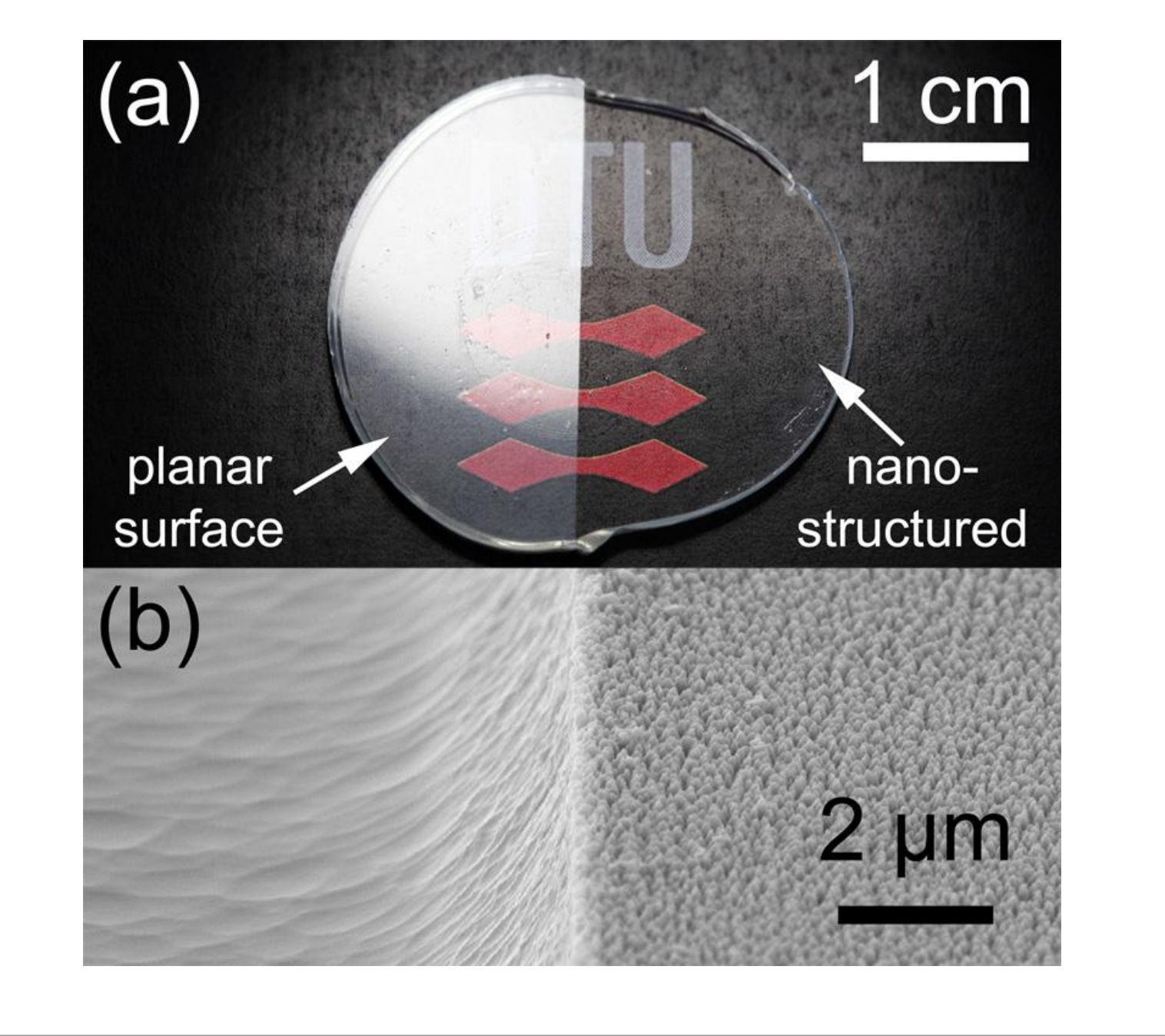
Integrated project PLAST4FUTURE (NMP2-

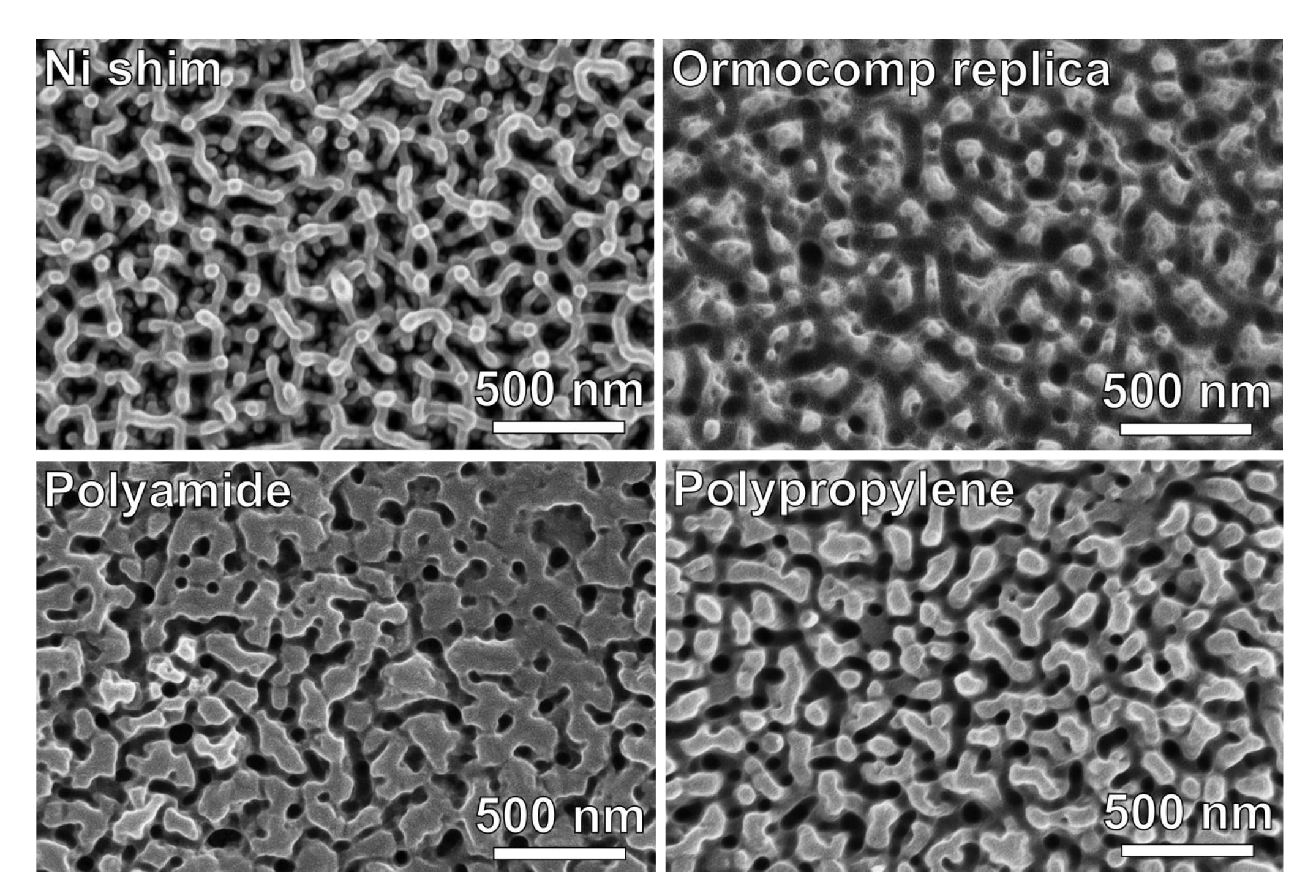

The SEM images offer a qualitative comparison of the different samples. The heights of the nanostructures were compared, from the AFM measurements. The filling of the injection moulded structures is $70 \%$ and $60 \%$ for polyamide and polypropylene respectively.

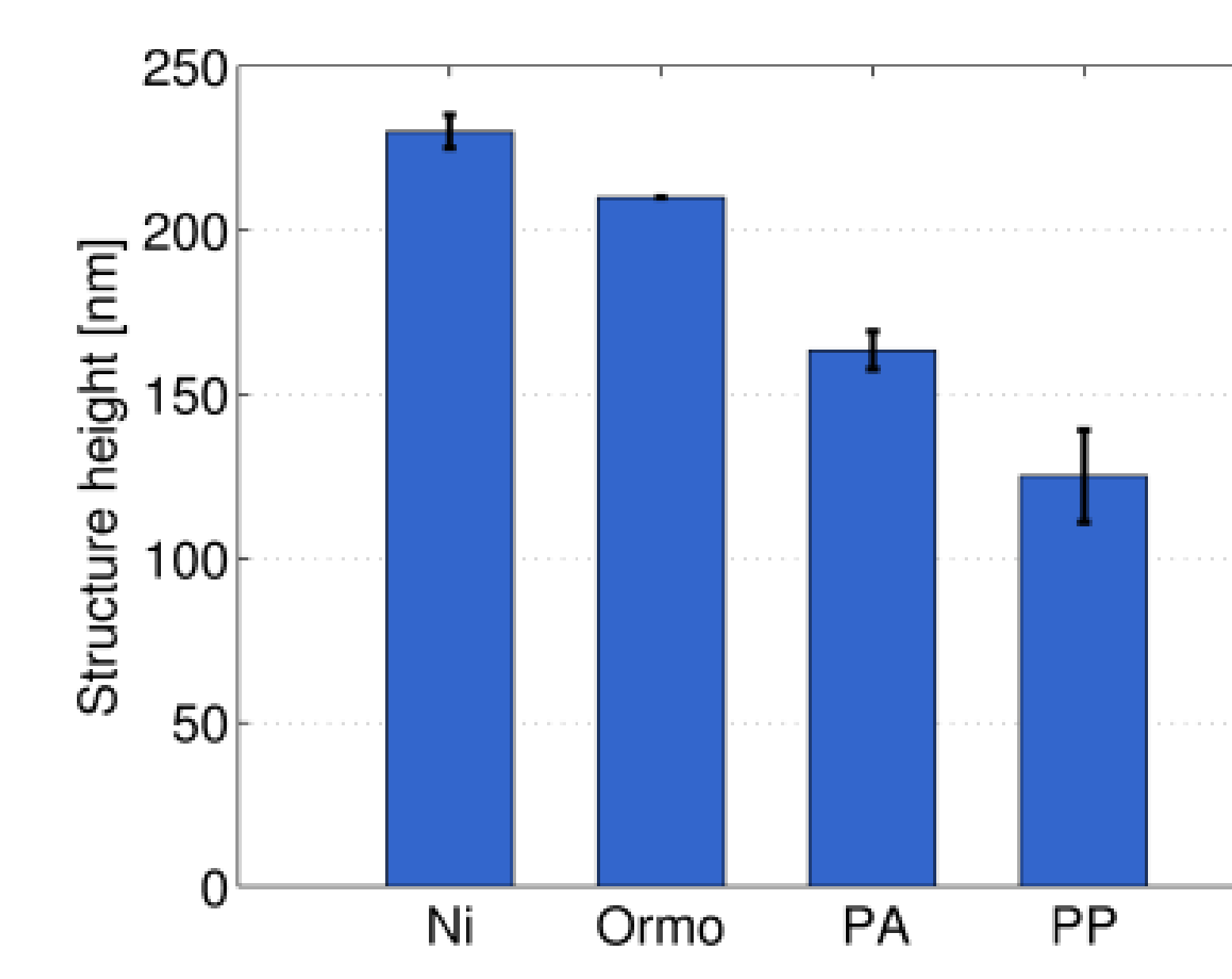

The injection moulded samples were microscope (SEM) and atomic force The structures were compared to the Nickel shim casted directly from the $\mathrm{Ni}$ shim (Ormocomp is a UV-curable resin from micro resist technology GmbH).

\section{Optical measurements}

The total reflectance of

the black injection moulded samples was measured using an integrating sphere.

The total reflectance of the polypropylene was reduced from $4 \%$ to below $1 \%$, due to the nanostructured surface.

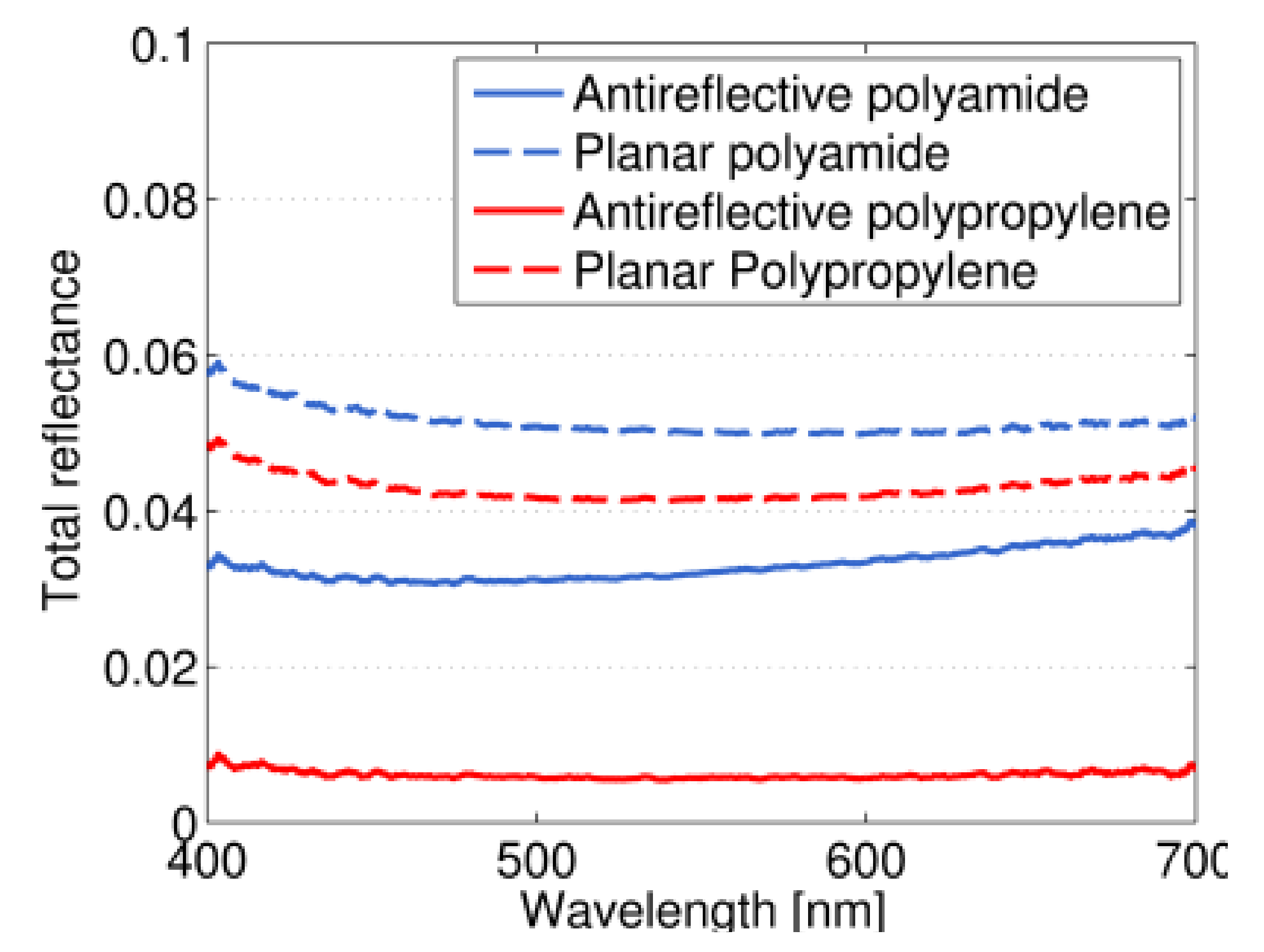

\section{Conclusion and outlook}

Nanostructures of $160 \mathrm{~nm}$ height and $200 \mathrm{~nm}$ period were injection moulded from a Ni shim. The filling of the injection moulded structures was $70 \%$ and $60 \%$ for polyamide and polypropylene respectively, when comparing to the $\mathrm{Ni}$ shim. The total reflectance of the polypropylene was reduced from $4 \%$ for a planar sample, to $1 \%$ for the injection moulded nanostructured sample.

In future work we will be injection moulding nanostructures in transparent polycarbonate, with the scope of increasing transmittance through the injection moulded substrates.

\section{Characterization}

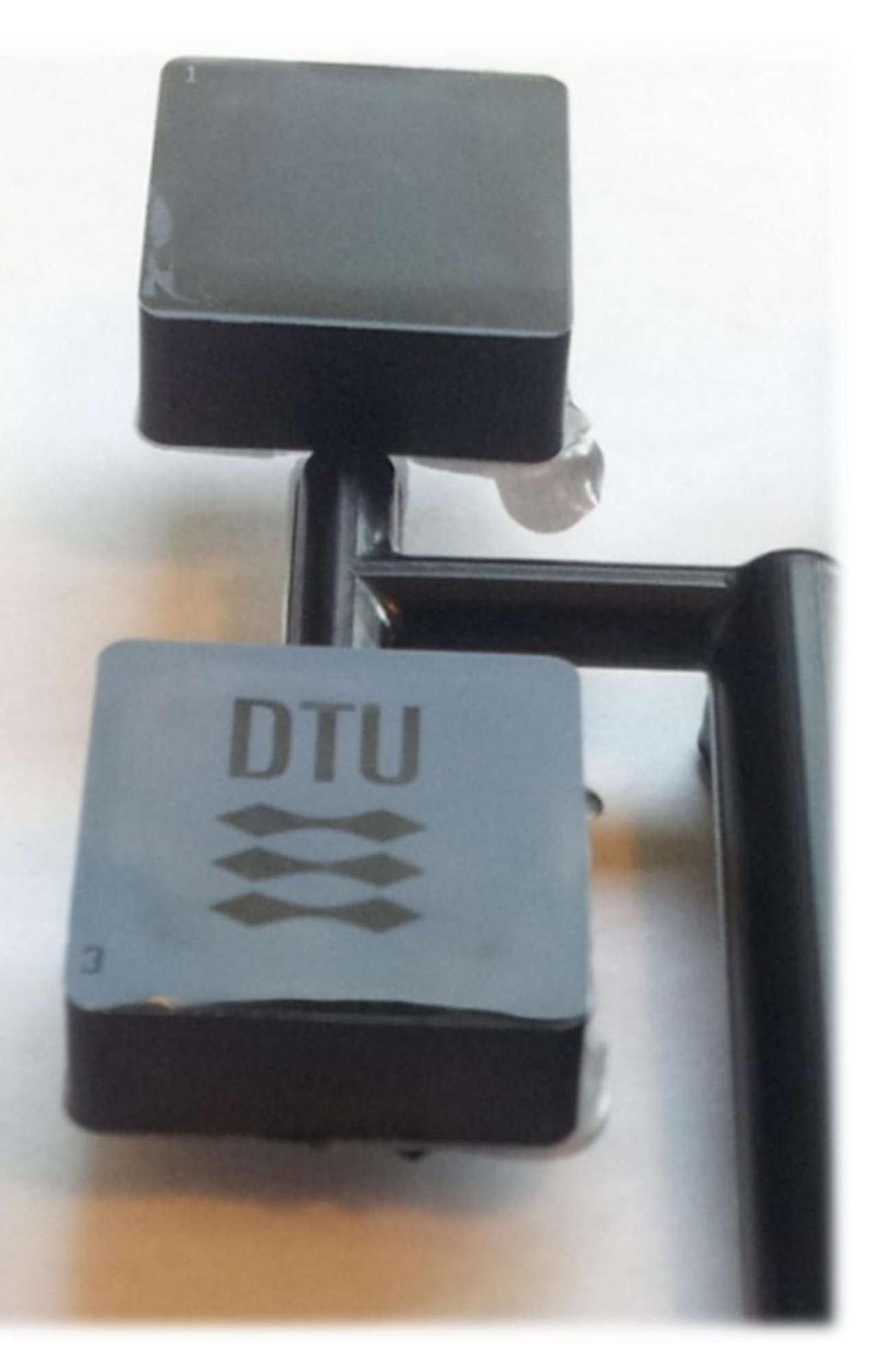

